\section{OBSERVATIONS ON SCURVY}

AS IT WAS DEVELOPED

IN BATH AND ITS NEIGHBOURHOOD, IN THE SPRING OF 1847.

By John Barrett, Esq., F.R.C.S.

(Read at the Quarterly Meeting of the Bath and Bristol Branch of the Provincial Medical and Surgical Association, December 21, 1848.)

In the autumn of 1847 , I promised $\mathrm{Mr}$. Farr,-to whom both the public and the profession are much indebted for his valuable share in the "RegistrarGeneral's Annual Reports"- that I would endeavour to obtain some information on the appearsnce of the land scurvy in this city and neighbourhood; and with this view $I$ sent a number of questions to various medical men whom I thought likely to assist me in the inquiry, and I have to acknowledge the courtesy and readiness with which they have given me their replies.

The land scurvy made its appearance in Bath and its neighbourhood about the middle of May, and had disappeared, I believe, by about the end of July, - that is, I do not learn that any new cases occured after this date, though the old ones were several of them still unrecovered. I do not mean to say that none of those cases occurred before May, presenting symptoms which, strictly speaking, constitute the first stage of land scurvy, and to which I shall presently advert, but up to this period those symptoms universally recognized as land scurvy had not arisen. Thus Mr. Gore, in his weekly report to the Board of Guardians, of the state of health in the Union House says, May 29th:"From some symptoms I have observed among the boys, I am impressed with the belief that they are beginning to suffer from the want of fresh vegetable food-ill supplied by the use of rice. Fresh lemons ordered for four of them who show signs of scurvy." But on June 6th he reports "six cases of land scurvy, one at least dangerous; independently of these, other inmates of the ward show more or less tendency to the same conditions."

One of my questions was-"Did you meet with cases in which, though there may not have been the swollen, red and bleeding gums, there was an anæmic state, attended with muscular or lumbar pains, waxy pallor, tendency to swelling of joints, weak pulse, languid respiration, tendency to fainting, and these symptoms unaccounted for by any particular loss of appetite or drain on the system?" Another question was-"Did you find that the diseases of the lower orders were, generally speaking, of an anæmic type?" And from the answers given to these questions I am led to conclude, that though the more marked symptoms of spongy bleeding gums, ecchymoses in the course of the tendons, \&c., were not observed till May, there had been during the spring, (to use the words of Dr. Shapter, in his interesting communication to the Provincial Journal at this period,) "indications of departure from the normal and healthy state of the blood, differing only in degree from that more marked deterioration in this fluid characteristic of the confirmed disease." I call your attention to the date of its marked appearance, because, according to Huxham and Lind, in their day, the latter part of the winter and the beginning of the spring was the time of its appearance. Probably the reason that it was observed in Bath at a later period of the year than that mentioned by writers of the last century, is to be found in the difference of the food. Undoubtedly the potato in our day is used to an extent it never was before. Formerly, therefore, when from the winter, people had been deprived of fresh vegetables for some months, they began to experience scurvy at the end of that season; but in our day, the potato being used during the winter, takes the place of fresh vegetables, and when towards the spring, from the insufficient supply, the price puts it out of the reach of the poor, then between the period which elapses before fresh regetables come in, that state of constitution arises, which terminates in direct scurvy under other circumstances favourable to its development. The cases I observed myself occurred about the end of May, and their history made good these observations.

To ascertain with any degree of exactitude the extent to which land scurvy prevailed, it would be necessary to determine the number of those cases already referred to indicating the same diathesis, but in a lower degree. I need hardly remark that this would be impossible, but from all I can learn from conversational or written inquiry, this diathesis did obtain to a very great extent in this neighbourhood in the early part of the year 1847. My brother, Mr. C. Barrett, surgeon to the Tisbury Union, informs me that about this time, a few cases of acute inflammation, when actively depleted speedily changed to the typhoid state, and a few days before death there were several blebs on the skin-those of pemphigus, except that their contents were a dark bloody serum. He had no severe cases of land scurvy, but there were many patients who suffered from the early symptoms. He remarks that there was a more than usual prevalance of purpura hæmorrbagica; and the same remark is made by Mr. Shorland, surgeon in the Westbury Union, who did not recognize any cases of land scurvy in that neighbourhood. Mr. Cockey, surgeon in the Frome Union, had two cases of land scurry, and a friend of his met with several cases of purpura hæmorrhagica. In the Keynsham Union, Mr. Hutchins observed several cases of land scurvy, but not of purpura hæmorrhagica; none of the scurvy cases were fatal. In the Camely Union several cases of land scurvy were observed by Mr. Perrin, two of 
which proved fatal. In the Bradford Union House, Mr. Highmore had sixteen or twenty cases; none were fatal.

I think it is questionable whether what is called purpura hæmorrhagica by these gentlemen, was not in reality land scurvy. It is not to be denied, that to most of us land scurvy was a new disease, and I consider the profession much beholden to Dr. Shapter for calling attention to it at the early period that he did. That some cases were returned as purpura hæmorrhagica, which were land scurvy, I can state with certainty, and I am free to confess that I did not immediately recognize its true character in the cases which came under my care. Whether there be any, or what is the essential difference, between purpura hæmorrhagica and land scurvy, I shall presently consider. I have taken some trouble to ascertain the number of cases of recognized land scurvy which occurred in Bath and that part of its neighbourhood comprised in the Bath Union. The population is upwards of 70,000, of which about 10,000 are agricultural. In the reports of the surgeons of the Bath Union, sixty cases are reported in the workhouse, and only two out of the house amongst the paupers of these only two were fatal. At the Bath United Hospital no cases occurred; * at the Bath General Hospital three, one of which proved fatal. At the other medical charities as far as I can judge, there may have been twenty-five cases, and I think that if I say about 120 recognized cases of land scurvy occurred in the district comprised by the Bath Union, I am about the mark. This would take in the cases met with in private practice.

When I commenced this enquiry I expected to find proofs of a prevalence of diseases of hæmorrhagic character. Such has not, however, been the case. Only two cases of purpura bæmorrhagica, and fifteen of other diseases of hæmorrhagic character, such as epistaxis, hæmatemesis, \&c., including apoplexy, are to be found reported as occurring at the Union House, during 1847 , the average number of inmates being 750. The number reported as occurring in the different districts of the Union during the same period, is two cases of purpura hæmorrhagica, and twenty-one of hæmorrhagic character, whilst the number of medical cases in the first quarter of 1847 , out of the bouse, was 663 .

At the Bath United Hospital, out of 14,918 cases, oply one was a case of purpura hæmorrhagica, and fortyone what I have called hæmorrhagic. At the Western Dispensary, out of 958, only three were hæmorrhagic ; and there was no case of purpura hæmorrhagica.

- In the conversation which followed, Dr. Davies stated that he had, as Physician to the Bath United Hospital, two cases which got well under the use of lemon juice. My information was derived from the books of the Hospital, in which no 6 ases are entered.
I think I am therefore justified in saying, that during 1847 there was rather an absence than a tendency to hæmorrhagic disease. What then is the nature of land scurvy? Dr. Budd, in his article "Scurvy," in the "Medical Library," says, p. 93, of scurvy and purpura, that they are "essentially different; they arise from different causes, they differ in the circumstances and mode of attack, and they require different treatment. We have already stated that the essential cause of scurry is prolonged abstinence from vegetable juices, and that the approach of the scorbutic habit is very gradual; purpura, on the contrary, often appears suddenly, and in many cases it cannot be attributed to any peculiarity in diet. Scurvy, when occurring on land, is, from circumstances we have before mentioned, met with almost exclusively at the end of winter, or in the early part of spring; purpura, on the other hand, is most common in summer and autumn. The livid and spongy state of the gums, which is pathognomonic of scurvy, and which, as well as the sallow and dusky hue, is a constant symptom of that disease, is not observed in purpura. Lastly, in scurvy, bleeding always does harm, and the disease is speedily cured by the use of succulent vegetables and fruits; while in purpura the abstraction of blood is often followed by relief, and the antiscorbutic juices are rarely, if ever, productive of much benefit."

I think that part of this diagnosis, resting on the character of treatment, is open to exception, but to this I shall have occasion to recur. On all hands it seems to be allowed, that land scurvy consists proximately in an altered state of the blood, which disordered state, says Dr. Shapter, "it would appear, from the investigations of Mr. Busk, mainly consists in the amount of fibrin, albumen, and salts and water, exceeding the proportion of health, while that of the Læmatosine falls below it." (Prov. Journal, 1847. p. 285.) That this is attended with, or followed very rapidly by, great debility, a general failing of the vital powers, and disorganization of the textures, must be allowed by all who have either witnessed cases of land scurvy, or read the accounts of it by others. Dr. Shapter says the disease "pritnarily consists in a peculiar state of anæmia," and I think this would express the view taken of it by Dr. Budd, in bis interesting article on "Scurvy," in the "Library of Medicine ;" but if we are to take anæmia in that sense in which it is generally understood 'by the profession, I think it is open to exception as a description of this disease. Thus we should say of a chlorotic girl that she was anæmic, and we should very few of us think of bleeding her. But I do not think that the facts and cases recorded bear us out in considering the anæmia of land scurvy parallel with this, though I think that Drs. Shapter and Budd consider it is.

Dr. Murray, in his interesting reports on the land scurvy when it appeared among our troops at the Cape 
of Good Hope, in the year 1839, (Med. Gaz., Vol. xx., p. 234,) says, "I have lately had an opportunity of seeing a good many cases of it in the civil and nilitary hospitals here, and from what $I$ have observed I think that physicians, divested of prejudice, who carefully study its pathology in the book of nature, will discover an intimate connection between it and disorders of the dyspeptic and melænic classes; and that by treating it as a primary sub-inflammatory or congestive affection of the chylopoietic organs, and rectifying gastric and hepatic derangement, direct improvement in the state of the blood (which is universally allowed to be vitiated in scorbutus,) will be the consequence, and various ameliorations in the nervous and vascular actions will speedily follow (if they do not even antecede, this salutary change in the blood;" and his view of the nature of land scurky appears to have been derived from, at any rate is borne out by, the success of treatment in accordance with it, as I shall presently notice.

Dr. Watson, in his last lecture on the "Principles and Practice of Physic," (Med. Gaz., Vol. xxx., p. 958,) adopts the view of Dr. Budd, as to the essential difference of purpura and land scurvy. "I formerly. regarded," he says, "the two affections as being identical, or as mere varieties of the same disorder; but it is not so." And he then refers to Dr. Budd's article. But it appears to me that his own successful practice might have shown him that the distinctions laid down by Dr. Budd between the two diseases, are hardly founded on reality. He mentions a case occur. ring under his care at the Middlesex Hospital, in the summer of 1830, where such cases were, it would appear, at that time exceedingly prevalent.

"The patient, a blacksmith, 35 years old, was covered with round purple spots, of various sizes, and with irregular blotches of ecchymosis. He had vomited blood on the preceding day. He was continually coughing up blood at the time of his admission, and his wife estimated the whole quantity that he had then lost to be more than half a pailful. The interior of his mouth and palate was pouring forth blood from a number of livid fungous tumours, formed by the extravasation of blood into the cellular tissue beneath the membrane, and the subsequent rupture of tbat membrane. He was passing blood by the bowels, and his urine was loaded with blood. Here were the symptoms of scurvy strongly marked. In the man's history we could trace its peculiar carse. He had long been subsisting on very poor and insufficient nutriment, seldom eating any meat, but living almost entirely on tea and coffee, and bread-and-butter. He had been too ill and weak to work regularly, yet he had been obliged occasionally to over-exert himself to obtain a scanty supply of food for himself, his wife, and a large family of children. He had been a settled dram-drinker, but for some time had taken much less of that stimulus, merely because he. had not the means of procuring it. His pulse was frequent and feeble." This patient was saved. "He was immediately put upon a diet of roast meat, and began to take daily half-a-pint of fresh. lemon juice, diluted with a pint-and-a-half of water, and some tonic medicine."

But Dr. Macmichael, in "Some Observations upon Land Scurvy," read before the College of Physicians April 25th, 1831, evidently referring to this case, says, “Dr. Watson's patient also was bled. And a boy admitted for scurvy under the care of Dr. Hawkins was bled, and used calomel and opium : here, too, the disease was cured." (Med. Gaz., Vol. viii., p. 185.) Both he and Dr. Watson (in his lectures,) refer to a case of Dr. Latham's, at St. Bartholomew's Hospital, termed "Purpura Hæmorrhagica":-

“February 12th, 1828. John Davies, aged 37, a linen-draper's shopman : every part of the body sprinkled over with purpurous spots, from the size of a flea-bite to that of a silver sixpence, and all of a livid colour; in the largest spots the livid colour is deepest at the centre, and fades towards the circumference. There are, besides, several darker patches upon the extremities, of a dusky hue, as if from a bruise. The gums livid and spongy, and blood oozing from their margins in contact with the teeth. The whole tongue livid, and one half presenting the appearance of a large, black, bleeding fungus, shooting from its surface, and the other half the same appearance in circumscribed spots. On the inner surface of each cheek several black fungoid patches. The soft palate clotted with black spots. Countenance sallow; conjunctiva rather tinged with bile, and having a small ecchymosis at the inner angle of each eye." To these symptoms were added vomiting and purging of blood. " He feels a consciousness of strength, and a great appetite for food, greater than in health. There is a fotid smell about him. Pulse 120, rather small but hard. Much general anxiety." (Med. Gaz., Vol. i, p. 544.)

The treatment consisted of bleeding to fifteen ounces, and two grains of calomel at a dose, and afterwards of seven grains of Hydrargyrum cum Creta, in doses of two grains and a half every six hours. He rapidly improved from this treatment.

Now, where is the essential difference in these cases : both present very much the same features, and are relieved, at least one of them, undeniably and in a marked manner, by the very remedies, one of which (bleeding,) it is stated always does harm in scurry, whilst "mercury," we are subsequently told by Dr. Budd, "in every form should be religiously aroided?" ("Libr. of Med.," p. 94.) I do not say there are no points of difference between the cases, for in Dr. Watson's case the affection came on gradually in a state of want, and in Dr. Latham's it appears to have occurred somewhat suddenly, and there is no mention of destitution. In both there seems to have been the bleeding gums, and that bloody kind of tumour which has had the name of bullock's liver given to it, and which I shall presently mention as having occurred in this neighbourhood. The terms hot and cold scurvy given to this complaint, show that it is not always of a passive character. 
Dr. Budd says, (p. 81,) "We have more than once observed, in sailors admitted into the Dreadnought, on account of scurvy, an extensive bruise mark on the knee or ankle, to which a blister had been applied some time previously, under the idea that the pains which the patient suffered in the $\operatorname{limb}$, and which in reality were scorbutic, were owing to inflammation affecting these joints. In such cases the blister rises well, discharges serum as usual, and heals readily; but in the course of some days the patient finds the part tender to the touch, and by observing that it is the seat of an extensive deep violet-coloured spot, first discovers the real nature of his complaint." But sometimes this inflammation is not imaginary. In two cases $I$ attended at the same time, swelling of the knee-joint occurred; in one, a man, both knees were swollen and weak, rather than painful; in the other, a woman, the left knee was swollen and painful, in short, presenting all the usual characters of synovial inflammation, and as such came under my care. It was only from the dark stains in the course of the hamstrings that I suspected the true nature of the case, and on examining the gums, and questioning her as to her food, \&c., I found the appearances and history of a well-narked case of land scurvy; still I treated this local affection as synovial inflammation, and relieved it, for I should remark that she was under my treatment some days before $I$ observed the appearance of the hamstrings, when I put her on citric acid, which, whilst I continued my attendance, was employed with advantage. But Dr. Budd himself remarks, that these extravasations are not altogether of a passive character. He says, - "The fluid poured out is not pure blood, which always remains soft, and in some measure liquid; nor serum, which causes œdema; but a fluid which glues the parts together, and gives a feeling of hardness." And he says of hot scurvy,- "In such cases when blood is taken from the arm, the clot contracts firmly, and has a buffy coat;" but, he adds, "it is to an inflammatory action, connected with the presence of these effusions, that we are inclined to attribute the fever in such cases." For the case of inflamed knee $I$ have mentioned, the extravasations in the course of the hamstrings were neither sufficient nor likely to produce synotial inflammation of the knee, and consequently, I look on such inflammation as a symptom of the disease,-as a more aggravated form of that affection of the joints common in these cases, and from its active character, indicating that the original disease is sometimes actire. And when we remember the close similarity of the symptoms in the cases of land scurvy and purpura $I$ have mentioned, as treated by Drs. Watson and Latham,'that in both these cases blood-letting, and in one of 'them also, mercury, was employed with adrantage, that in other cases occurring at the Middlesex Hospital at the same time as Dr. Watson's, these depletory remedies were also successfully employed, we shall, I think, conclude that there is not so evidently an essential difference between the two diseases, at any rate, that we cannot found this difference on a treatment peculiar to each, but that at least sometimes land scurvy greatly resembles purpura, not only in particular symptoms, but also in that both are re. mediable by treatment of the depletive character, the value of which, in purpura, I would remind you, was first pointed out by a Bath physician, and consequently, that both occasionally partake in the same, that is, sthenic, diathesis.

This question of the nature of the disease is no mere theoretical one, and that must be my excuse for dwelling so long upon it. Good common sense is, I believe, so distinctive a feature of medical men, that there are few of them who would long allow theory to contradict the plain indications of disease; still misconceived notions will naturally have their weight, and in a disease which is not of every day occurrence, it is doubly necessary that our preconceptions of its nature be correct. What then is the indication of treatment in land scurry? If it be originally an asthenic disease, we shall use sthenic treatment, but if its asthenic character be not primary, but rather the result of original derangement, then there may be a stage, and there may be cases presented, to us, in which depletive treatment is necessary. Nothing can be more distant than the views taken on this very practical question. On the one hand Dr. Budd says, ("Library of Medicine, p. 94,) "Bleeding should never be had recourse to, although acute pains, heat of skin, quickness of pulse, and other febrile symptoms of a dangerous hæmorrhage may seem to render it advisable. In advanced stages of the disease patients do not survive it ; blisters are apt to produce gangrene, and for this reason we should abstain from their employment. Mercury, in every form, should be religiously aroided ; even in very small quantities it has been known to produce dangerous salivation. We have met with instances in which scorbutic symptoms seemed to have been much aggravated by mercury taken before the scurvy made its appearance. The ill effects of this medicine are indeed noticed by most writers on scurry; and Kramer, who was physician to the imperial armies in Hungary, from 1720 to 1730 , relates that of $\mathbf{4 0 0}$ men affected with genuine scurvy, to whom, on the advice of Boerhaave, mercury was given, so as to induce salivation, not one survived." · Nothing can be stronger than the words of this old author;"Beware of bleeding : shun mercury as poison." But when we turn to the army reports, furnished by Dr. Murray, we find just as strong a recommendation of the antiphlogistic treatment. Thus Mr. Samuel Bailey, surgeon, R. N., says,- " I shall briefly state, that since the beginning of this year, I have made a fair comparative trial of the tonic and antiphlogistic modes of 
treatment, in sea scurvy, and that the superiority of the latter has been very marked. To a certain number of the cases I allowed a full ration of fresh meat, with soup, tea, bread, vegetables, fruit, (i.e., grapes and lemons,) and beer, and gave them occasional doses of aperient medicine and quinine; and to another certain number labouring under similar symptoms, I ordered low diet, without any animal food, but with the same allowance of vegetables and fruit, and treated them medicinally by small bleedings, (where the breathing was oppressed,) mercurial alteratives, antimonials, and a full purgative dose of Epsom salts every morning. The result was, that in the former the oppression of bleeding did not subside; the appetite in the majority failed; their strength and activity improved very slowly; indeed, in two individuals, rather diminished; their skin kept dry and rough; their gums continued spongy; the lividity, weakness, and rigidity of the limbs, made scarcely any progress towards recovery; their despondency and unhealthiness of complexion continued; their sleep was unrefreshing; in short, their convalescence wąs protracted, and very imperfect, whilst those under the antiphlogistic plan (who, by the by, grumbled sadly at first at their getting low diet, as the others had full,) recorered in a very rapid and satisfactory manner. Their appetite and strength improved daily; their breathing became free; their countenance clear and lively; their pulse, urine, and alvine secretions, natural; and I may say, most of them were fit to be discharged to their duty before those on the tonic plan were able to leave their beds. These patients were carefully watched by some of $\mathrm{my}$ medical friends, known for their independence of thought and talent for observation, who all perfectly agreed with me as to the superiority of the antiphlogistic treatment."-Medical Gazette, vol. xx., p. 235.

The same plan of treatment, with occasionally mild mercurial treatment, with the same happy results, was adopted by other medical officers at the Cape, and the detail of the symptoms would leave no doubt on the mind that the disease they were treating was the same as that in which bleeding and mercury have been so strongly condemned. One of my correspondents, $\mathbf{M r}$. Perrin, of Camely, surgeon to the Union House, met with several cases of land scurvy in the workhouse and district, attended with spongy bleeding gums, and in the advanced stage, sloughing of the cheeks to a frightful extent. At first he treated it too much as a disease of debility, and ordered tonics, with lemon juice, and potatoes, but with little success. Afterwards he used rhubarb, and Hydrargyrum cum Creta, pretty frequently, with now and then a brisk purge, and good strong lotions of alum water, and found himself much more master of the complaint than under the first plan of treatment, and without the potato or lemon. Two cases were fatal, and he considers that he put these on the stimulant and tonic plan too soon, though in all cases, of course after due attention to the bowels, he made their living generous, for he remarks, that the diseases of the last year were all decidedly of an anæmic character, and very few stood steady depletion for any length of time.

There is certainly no small difficulty in reconciling these different views of treatment; I would, however, suggest, whether the cases coming under Dr. Budd, at the Dreadnought, and which ,were principally seamen from merchant vessels, are not likely to have been in a more advanced stage of the disease, and consequently, with the powers of life more broken down, than the patients of medical officers at the Cape, or than my correspondent, Mr. Perrin's patients. They probably had, for some time before treatment was commenced, been suffering from it, and the stage in which depletion is right may have passed, and have left a state in which it could not be borne. We know how much the question has been mooted, whether bleeding is right in cholera. From cases which came under my observation, whilst a pupil in town, I was satisfied that there was at least sometimes a stage in which it might be used with advantage, but this rapidly passed off. I do not mean to say that in land scurvy this stage passes off with anything like the same rapidity, but merely that cases of decidedly the same disease may have been differently treated with success, from their being met with in different stages; and $I$ am the more induced to take this view of the difference of opinion by observing, that one of the medical officers at the Cape, who seems to favour the tonic plan, was surgeon to the hospital where the patients affected with land scurvy were received from the outposts; they were not cases originating in the hospital, and consequently had been some time affected when they came under his care. "I have no doubt," he says, "that had either bleedings, or strong saline purges, been used in the severe cases, they would have sunk; and I further think, that if a rein had been opened, it would not have united; in short, that the antiphlogistic practice would not have been advisable in any of these cases. The rapidity of recovery effected by change of air, comfortable quarters, the liberal use of port wine, and such like treatment, was surprisingly great, except in the man who was in a moribund state at the time of his admission into my hospital."-Medical Gazette, vol. $x \times .$, p. 942. It appears to me that this may be perfectly correct, and yet that these very cases may have previously presented symptoms indicating depletion.

The practice at the Cape, which consisted principally in bleeding and saline purges, was, in truth, antiphlogistic. Mercury does not seem to have been often used; but I have brought forward proofs that it may be used with advantage in this disease, though proscribed in the strong language I have quoted from the old author Kramer, and adopted by Dr. Budd. "Shun mercury as you would poison." Perhaps, if 
Dr. Budd's objection to it be founded on practice, it may bear the same explanation $I$ bave given of bis objection to bleeding, - that his cases had passed the stage when depletion could be borne; and in judging the value of an opinion on the use of mercury some hundred years ago, we must take into consideration the modes of employing it now, and then. A knowledge of what mercury can do when properly used, and what it will do when improperly used, is amongst the best proofs of our improvement in medical science-it is at once the most remedial and destructive agent we can employ, because its effects are most definite; and if Kramer saw it used in land scurvy in anything after the fashion it was used amongst us some fifty years ago, it is no very great wonder he should have reprobated it in a disease so rapidly tending to depression.

But there is one remedy which has met with nearly unirersal approbation-citric acid or lemon juice; it would appear to have been used by the medical officers at the Cape, in conjunction with their antiphlogistic plan; and all parties seem to consider, that whatever may be the proximate cause of the symptoms of land scurvy, and consequently the indications of treatment to be derived from diathesis, the primary cause is the want of some principle in the animal economy which an organic acid supplies, and that none is equal to the citric acid. In the cases which came under my own treatment, but which were not aggravated in their symptoms, I found the citric acid of commerce sufficient. Mr. Harries, of this city, informs me that he did also, though he continued it for a long time it would seem before it fully effected a cure. But some of my correspondents employed the fresh lemon. $\mathrm{Mr}$. Gore ordered fresh lemons and green vegetables for the cases at our Union House.

Mr. Highmore, of Bradford, first treated the disease in the Bradford Union House by a total change of diet, giving fresh regetables, and citric and mineral acids, quinine and other tonics, without the slightest ruccess. He then obtained a supply of lime juice, which was given to all the children, healthy and diseased, two onnces to each daily, with sugar and water. After the first few days from adopting this plan, no fresh case occurred, and it was sufficient to cure those already ill, some of whom were in a most pitiable condition, the spongy bleeding gums overlapping the teeth, and the cheeks, in two cases, deeply ulcerated. But other acids were employed with success.

Mr. Foster, the surgeon to the Taunton Union House, informed me that be made the patients there drink rough cider, and eat plenty of fresh regetables, and they got well. My brother, (Mr. C. Barrett,) in the Tisbury Union, employed sulphuric acid, vegetable diet, and tonics, with speedy relief. Dr. Lindoe, physician to the Walcot Dispensary, met with about a dozen cases which he recognized as land scurvy, but he states that he found more than a usual prevalence of purpura hæmorrhagica. His treatment consisted in saline diaphoretics, with acidulated drinks, followed by vegetable tonics and diluted mineral acids. Dr. Samuel Edwards, of London; late physician to the same dispensary, writes me that he treated bis cases, which were not aggravated ones, on the tonic pfan, vegetable bitters, with mineral and regetable acids, but, above all, the "Charity Ball" tickets, by which means he was able to supply good meat soup, meat, and sometimes vegetubles. Mr. Hutchins, surgeon to the Keynsham Union House, where the disease appeared, informs me that medicines were not generally well borne. He used alteratives, slight purgative, tonics, with light nutritive diet and stimulants. His cases were of slight character.

\section{(To be continued.)}

\section{CASE OF EMPYEMA,}

IN WHICH NINETEEN PINTS AND A HALF OF PUS WERE REMOVED BY AN OPENING MADE INTO THE CAVITY OF THE CHEST, WITH REMARKS,

\section{By Jokn Tucker, Esq., Surgeon to the Exeter Dispensary.}

(Read to the Devon and Exeter Pathological Society, at the Exeter Dispensary, Pebruary 2nd, 1849.)

The attention of medical practitioners having been of late frequently called to empyema and paracentesis thoracis in several of the medical publications, induces me to relate to the members of this Society a case which some time since occurred in my practice. There are many remarkable circumstances with which it is connected, so that I venture to anticipate a brief report of it will not be considered as uninterestitig by the majority now assembled.

On the 30th of June, 1837, James Tucket, aged 26, of Ashton, in this county, consulted me. A few days previously he returned from the Island of Jamaica, where he had spent the last six years in the capacity of an overseer, which in the West Indies is understood as the manager of an estate. I had known him well before he left Englund, when he was in rude health and had never shown any predisposition to disease. The change now, however, which had taken place in his constitution, forcibly struck me, for his general appearance was that of a person in the last staje of phthisis, and so were his symptoms, for he had a most harrassing cough, great emaciation, pulse 130, cedematons state of the legs, and expectorating daily from a pint to a pint and a half of purulent matter.

The history he gave me of his case was as follows :That for more than twelve months he had been in an ailing state, suffering from boils in various parts of his body, which were relieved by occasional doses of blue pill and laxative medicine. These disappearing, slight pains were often felt in the left side just below the ribs, and which increased when he coughed or laughed. 